\title{
Nulidad objetiva de la extinción del contrato \\ en período de prueba de la trabajadora embarazada
}

\author{
Objective nullity of the extinction of the contract \\ in the probation period of the pregnant worker
}

\author{
MARÍA DogANoc DE LEÓN * \\ Letrada de la Administración de Justicia \\ Servicio Común de Notificaciones y Embargos \\ de los Juzgados de lo Social Barcelona
}

Recibido: 06/07/2019

Aceptado: 20/01/2020

doi: https://doi.org/10.20318/femeris.2020.5390

\begin{abstract}
Resumen. Tras la reforma del artículo 14 del Estatuto de los Trabajadores llevada a cabo por el Real Decreto-ley 6/2019, de 1 de Marzo, de medidas urgentes para garantía de la igualdad de trato y de oportunidades entre mujeres y hombres en el empleo y la ocupación, en relación a la nulidad de la extinción del contrato de trabajo por desistimiento del empresario durante el período de prueba de la trabajadora embarazada, se analiza en el presente trabajo la evolución legislativa y jurisprudencial en la materia, con especial referencia a los votos particulares emitidos en su día por los Magistrados que, juzgando con perspectiva de género, se apartaron de la decisión mayoritaria de la decisión adoptada por el Tribunal Supremo mediante Sentencia de 18 de Abril de 2011 y del Tribunal Constitucional en Sentencia de 10 de Octubre de 2013.

Palabras clave: nulidad objetiva, despido, período de prueba, embarazada.

Abstract. After the reform of article 14 of the Workers' Statute carried out by Royal Decree-Law 6/2019, of March 1, on urgent measures to guarantee equal treatment and opportunities between women and men in employment and the occupation, in relation to the nullity of the termination of the employment contract due to the withdrawal of the employer during the probationary period of the pregnant worker, is analyzed in this work the legislative and jurisprudential evolution in the matter, with special reference to the votes individuals issued at the time by the Magistrates who, judging from a gender perspective, departed from the majority decision of the decision adopted by the Supreme Court by Judgment of April 18, 2011 and of the Constitutional Court in Judgment of October 10, 2013.

Keywords: objective nullity, dismissal, trial period, pregnant.
\end{abstract}

"mariadoganoc@hotmail.es 


\section{Introducción}

El riesgo de pérdida del empleo como consecuencia de la maternidad constituye el problema más importante -junto a la desigualdad retributiva- con el que se enfrenta la efectividad del principio de no discriminación por razón de sexo en el ámbito de las relaciones laborales ${ }^{1}$.

Es un hecho objetivo y notorio que la situación de embarazo de la mujer afecta a su vida profesional, por lo que en aras de conseguir una efectiva igualdad entre el hombre y la mujer, dicha situación debe ser objeto de una protección integral.

Para lograr esa efectiva igualdad que se proclama, debe tenerse presente que la idea de retrasar el momento de la maternidad en muchas ocasiones va asociada al miedo a perder su puesto de trabajo, o a los inconvenientes y problemas que se va a encontrar para poder conciliar su vida laboral con la familiar. Por tanto la idea esencial debe ser el considerar que la decisión de formar una familia no suponga para la mujer trabajadora tener que renunciar a su carrera profesional -en determinadas profesiones, aunque no se prohíba directamente el acceso a las mujeres, se les obliga a seguir un patrón masculino, por ejemplo, renunciando a la maternidad ${ }^{2}$ - ni que a partir de ese momento se tenga que desdoblar para poder compatibilizar su trabajo con la debida y necesaria atención a su nueva familia.

Ofrecer las mismas oportunidades a todos por igual no significa que todos podran disfrutar y ejecutar estos derechos formales de la misma manera. La política de igualdad de oportunidades no tiene en cuenta la existencia de condiciones materiales que impiden a las mujeres ejercitar sus derechos y obtener acceso igualitario a las oportunidades que se les ofrece. ${ }^{3}$

En el informe elaborado por la Organización Internacional de Trabajo publicado el 13 de Mayo de $2014^{4}$ se hacía constar que en Croacia, Grecia, Italia y Portugal se había denunciado el uso de "renuncias en blanco", una carta de renuncia sin fecha, que las trabajadoras se veían forzadas a firmar al momento de su contratación, y que se utilizaba para dejarlas sin trabajo en caso de embarazo, enfermedad de larga duración o responsabilidades familiares.

Por todo lo anteriormente expuesto es relevante la reforma llevada a cabo mediante el Real Decreto-ley 6/2019 del articulo 14 del Estatuto de los Trabajadores en relación a la aplicación de la nulidad objetiva a la extinción del contrato de trabajo por desistimiento del empresario durante el período de prueba, todo ello en vías de lograr una efectiva igualdad de oportunidades a nivel laboral entre mujeres y hombres.

\footnotetext{
${ }^{1}$ STC de 6 de Mayo de 2009.

${ }^{2}$ Lousada Arachena, J.F., "Estereotipos de género y concepto de discriminación por razón de sexo”. Cuadernos Digitales de Formación, no 30, 2016. Consejo General del Poder judicial, pág.1. Señala que se refiere al doctrinalmente denominado "dilema de Wollstonecraft" según el cual las mujeres deben escoger entre dos alternativas: o son como los hombres y acceden plenamente a la ciudadania -asimilacionismo- o continúan en el trabajo domestico, sin valor para la ciudadania.

${ }^{3}$ Jiménez Hidalgo, A. “Juzgar con Perspectiva de Género en la Jurisdicción de lo Social”. pág.10. Asociación de Mujeres Juezas (AMJE) www.mujeresjuezas.es

4 "La maternidad y la paternidad en el trabajo. La legislación y la práctica en el mundo". Informe de la Organización Internacional del Trabajo publicado el 13 de Mayo de 2014. Resumen. Pág.11. www.ilo.org.
} 


\section{Situación legal y jurisprudencial antes de la promulgación del Real Decreto-ley 6/2019, de 1 de marzo de medidas urgentes para garantia de la igualdad de trato y de oportunidades entre mujeres y hombres en el empleo y la ocupación}

Establecía el articulo 14 del Estatuto de los Trabajadores -precepto que regula el período de prueba- en su párrafo segundo que "Durante el período de prueba, el trabajador tendrá los derechos y obligaciones correspondientes al puesto de trabajo que desempeñe como si fuera de plantilla, excepto los derivados de la resolución de la relación laboral , que podrá producirse a instancia de cualquiera de las partes durante su transcurso".

Es decir, que durante dicho período el contrato podía ser resuelto a instancia de cualquiera de las partes sin excepción alguna y sin necesidad de preaviso salvo que específicamente así se hubiera establecido.

Por otro lado, el párrafo $4^{\mathrm{o}}$ del artículo 53 del E.T., en relación al despido objetivo, dispone que "Cuando la decisión extintiva del empresario tuviera como móvil algunas de las causas de discriminación prohibidas en la Constitución o en la ley o bien se hubiera producido con violación de derechos fundamentales y libertades públicas del trabajador, la decisión extintiva será nula, debiendo la autoridad judicial hacer tal declaración de oficio", disponiendo que será también nulo el despido el los supuestos que enumera, regulando el apartado b) la nulidad objetiva del despido en caso de las trabajadoras embarazadas $^{5}$. En idéntico sentido se regula en el apartado b) del párrafo 5ํ del artículo 55 en relación al despido disciplinario.

La STS de 18 de Abril de 2011, nº rec. 2893/2010, analizó la posibilidad de extender la nulidad del despido de la trabajadora embarazada a la extinción del contrato durante el período de prueba.

La Sala, tras recordar el tratamiento jurisprudencial y constitucional del despido de la mujer durante la gestación, destacando que la tutela se había diseñado en principio exclusivamente para el despido en sentido estricto (disciplinario u objetivo), y analizar la naturaleza jurídica del desistimiento empresarial durante este periodo, llega a la conclusión de que ambas instituciones presentan diferencias sustanciales -relativas a las formas a las que debe sujetarse el despido, no así el desistimiento, y a las consecuencias de la ilicitud de la extinción- que permiten afirmar que el periodo de prueba supone una excepción al principio de prohibición de libre extinción del contrato para el empresario, por lo que la posibilidad de transponer a dicho periodo el régimen jurídico del despido queda excluida respecto de aquello en lo que no haya igualdad de razón jurídica como es el caso, sin que la ampliación de supuestos de nulidad del despido que arranca de la Ley 39/1999 (ampliada en la LO 3/2007) haya alcanzado a esta extinción. Concluye la sentencia que no cabe, por

\footnotetext{
${ }^{5}$ Será también nula la decisión extintiva en los siguientes supuestos:

b) La de las trabajadoras embarazadas, desde la fecha de inicio del embarazo hasta el comienzo del periodo de suspensión a que se refiere la letra a); el de las personas trabajadoras que hayan solicitado uno de los permisos a los que se refieren los artículos 37.4, 5 y 6, o estén disfrutando de ellos, o hayan solicitado o estén disfrutando la excedencia prevista en el artículo 46.3; y el de las trabajadoras víctimas de violencia de género por el ejercicio de su derecho a la tutela judicial efectiva o de los derechos reconocidos en esta ley para hacer efectiva su protección o su derecho a la asistencia social integral.
} 
tanto, extender el blindaje propio del despido. La sentencia tiene voto particular a favor de la extensión pretendida.

La referida STS fue recurrida en amparo, habiéndose dictado STC 173/2013 de 10 de Octubre, denegando el amparo solicitado por la trabajadora recurrente. Considera el TC que la extinción del contrato durante el periodo de prueba será nula (como cualquier otra decisión extintiva) si se produce con vulneración de derechos fundamentales, como sucederá si la decisión empresarial es una reacción al embarazo de la trabajadora (STC $17 / 2007$, de 12 de febrero). Ello sentado, y aplicando la doctrina constitucional en materia de discriminación por razón de sexo de las trabajadoras embarazadas (por todas, STC 17/2003, de 30 de enero), entiende el Tribunal que en el presente caso no existían indicios de discriminación, pues no ha quedado acreditado que la empresa conociera el embarazo de la trabajadora y que, aunque se hubiera afirmado la existencia de indicios, resulta que en la misma fecha de extinción del contrato de la recurrente se extinguió también por el mismo motivo el contrato de otro trabajador, contratado en idénticas condiciones y fechas, dándose en ambos casos la circunstancia de que no se habían alcanzado los objetivos mínimos fijados en el contrato, lo que excluiría el pretendido móvil discriminatorio de la decisión extintiva.

Ambas resoluciones fueron objetos de votos particulares que por su contenido y por entender que en dichos casos se juzgó con perspectiva de género, serán objeto de análisis en el presente trabajo.

\section{STS 18 de Abril de 2011 y voto particular}

En la Sentencia del Tribunal Supremo de fecha 18 de Abril de 2011, sentencia que desestimó la demanda instada por una trabajadora que prestaba servicios como comercial y a la que se le comunicó la extinción del contrato de trabajo por no superación del período de prueba, se dictaminó que no cabía extender el blindaje propio del despido al supuesto analizado, de extinción del contrato de trabajo durante el período de prueba.

Realiza la sentencia un análisis de la evolución jurisprudencial y constitucional del despido de la mujer durante la gestación ${ }^{6}$, antes de pronunciarse sobre la posibilidad de

\footnotetext{
6 "A raíz de la Ley 3/1999, de 5 de Noviembre, para promover la conciliación de la vida familiar y laboral, el Estatuto de los Trabajadores incorporó concretas medidas de protección eficaz a favor del principio de igualdad de oportunidades en el empleo de las mujeres. En particular, y ciñéndonos exclusivamente a la extinción del contrato de trabajo de la trabajadora embarazada, se produjo la inclusión de un supuesto de nulidad del despido que venía a añadirse al ya contemplado en el apartado 5 del art.55 ET.

La interpretación del nuevo texto legal llevó en un principio a esta Sala IV a sostener que era preciso que el empresario conociera el embarazo de la trabajadora y que, si tal conocimiento existía, la ley establecía una presunción iuris et de iure de móvil discriminatorio, de suerte que la nulidad sólo estaria excepcionada de acreditarse la procedencia del despido (....).Partía allí la Sala de considerar que el despido de la mujer embarazada constituía un supuesto particular de despido discriminatorio y rechazaba de este modo la tesis de la "nulidad objetiva", que abogaba por aplicar la nulidad prescindiendo del móvil de la decisión extintiva.

Esta postura jurisprudencial fue rectificada en la STS de 17 de Octubre de 2008 - rcud.1957/2007 (...)en la que se acogía el criterio de la STC 92/2008, de 21 de Julio. En ésta última el Tribunal Constitucional entró a valorar el alcance del art.55.5 ET para sostener que el legislador optó por un desarrollo del art.14 CE incrementando las garantías al no exigir el
} 
su aplicación al supuesto de desistimiento empresarial durante el período de prueba, para posteriormente rechazar tal aplicación en base a los siguientes argumentos:

- Que ni la Ley 39/1999, ni la ulterior L.0.3/2007, de Igualdad efectiva de mujeres y hombres -que amplió sustancialmente los supuestos de "nulidad objetiva" de los arts.53.4 y 55.5. E.T. con una misma finalidad-, ni las demás reformas operades posteriormente en el E.T. han incidido en otras causas de extinción de la relación laboral.

- Que el legislador nacional sólo ha ampliado la protección para los supuestos de despido causal y, por tanto, la extensión a otras causas de extinción habrá de hallar apoyo en la detección de los elementos sobre los que asentar una aplicación analógica como la que permite el articulo 4.1 del Código Civil, la cual procede cuando las normas no contemplen un supuesto específico, pero regulen otro semejante entre los que se aprecie la identidad de razón.

Tras analizar la naturaleza jurídica del desistimiento empresarial durante el período de prueba, llega a la conclusión de que ambas instituciones presentan diferencias sustanciales -relativas a las formas a las que debe sujetarse el despido, no así el desistimiento, y a las consecuencias de la ilicitud de la extinción- que permiten afirmar que el período de prueba supone una excepción al principio de prohibición de libre extinción del contrato para el empresario, por lo que la posibilidad de transponer a dicho período el régimen jurídico del despido queda excluida respecto de aquello en lo que no haya igualdad de razón jurídica como es el caso analizado, sin que la ampliación de supuestos de nulidad del despido que arranca de la Ley 39/1999 (ampliada en la L.0 3/2007) haya alcanzado a esta extinción.

Esta sentencia fue objeto de un voto particular $^{7}$ que se pronunció a favor de la aplicación de la nulidad objetiva fijada para el despido en el caso analizado de extinción de la relación laboral durante el período de prueba, siendo sus argumentos los que seguidamente se relacionan:

- Entienden los Magistrados firmantes del voto particular que el articulo $10.2^{8}$ de la Directiva 1992/85/CEE del Consejo, de 19 de Octubre de 1992, relativa a la

requisito de la previa notificación del embarazo al empreario por parte de la trabajadora. Rechazando la suficiencia de los criterios interpretatives contrarios -y entendiendo vulnerado por ello el art.24 CE-, concluía así el TC que el legislador ha relevado a la trabajadora embarazada de la prueba del conocimiento de su embarazo por parte de la empresa.

Posteriormente la STC 124/2009, de 18 de Mayo, anuló la STS de 19 de Julio de 2006 (rcud.1452/2005) y reiteró el mismo criterio de la STC $92 / 2008$

${ }^{7}$ Formulado por el Magistrado Fernando Salinas Molina, Luis Fernando de Castro Fernandez, Jordi Agustí Julia, María Luisa Segoviano Astaburuaga, Rosa María Viroles Piñol y Manuel Ramon Alarcon Caracuel.

8 "Como garantia para las trabajadoras a que se refiere el art.2 (trabajadora embarazada, que haya dado a luz o en período de lactancia), del ejercicio de los derechos de protección de su Seguridad y salud reconocidos en el presente articulo, se establece lo siguiente: 1) Los Estados miembros tomarán las medidas necesarias para prohibir el despido de las trabajadoras, a que se refiere el art.2, durante el período comprendido entre el comienzo de su embarazo y el final del permiso de maternidad a que se refiere el apartado 1 del art.8 salvo en los casos excepcionales ni inherentes a su estado admitidos por las legislaciones y/o prácticas nacionales y, en su caso, siempre que la autoridad competente haya dado su acuerdo. 2) Cuando se despida a una trabajadora, a que se refiere el art.2,durante el período contemplado en el punto 1, el empresario deberá dar motivos justificados de despido por escrito. 3) Los Estados miembros tomarán las medidas necesarias para protegir a las trabajadoras, a que se refiere el art.2, contra las consecuencias de un despido que sería ilegal en virtud del punto 1 “. 
aplicación de medidas para promover la mejora de la Seguridad y de la salud en el trabajo de la trabajadora embarazada, que ha dado a luz o en período de lactancia, suministra una base interpretativa sólida para deducir que en aquellas legislaciones nacionales de los Estados comunitarios en los que la extinción del contrato de trabajo por despido o destitución o desistimiento empresarial no exija la concurrencia de una causa justa, atribuyendo a la libertad organizativa empresarial la decisión de despedir, destituir o extinguir sin necesidad de motivos justificados, cuando se pretenda despedir, destituir o extinguir el contrato a una trabajadora embarazada, que haya dado a luz o en período de lactancia, en todo caso exigirá que el empresario deba "dar motivos justificados de despido por escrito" -tal como señala el precepto referido-.

- Y sigue diciendo, que si la Directiva resulta aplicable a los supuestos de extinción que necesiten justa causa, parece claro que también lo debe ser a los supuestos de extinción en período de prueba, tanto si se considera que dicha extinción es causal (por no haber superado la prueba) como si se estima que, en realidad, el empresario puede extinguir libérrimamente (sin justificar la no superación de la prueba) la relación laboral durante el período de prueba.

- Y, en consecuencia, tal como manifiestan, si es aplicable la Directiva comunitaria, es claro que también lo es la normativa nacional de trasposición de la misma, el art.55.b) E.T, en los términos establecidos por la Ley 39/1999, de 5 de novembre, de conciliación de la vida familiar y laboral, y con la modificación posteriomente introducida por la L.0. 3/2007, de 22 de marzo, para la igualdad efectiva de mujeres y hombres, según el cual será nulo el despido de la trabajadora embarazada desde la fecha de inicio del embarazo, sin que el precepto exija la necesidad de acreditar que el empresario era conocedor de dicha circunstancia.

- Consideran los Magistrados firmantes del voto particular que dicha interpretación es coherente con una difundida doctrina según la cual el "despido" es un concepto genérico equivalente a denuncia unilateral empresarial, que engloba todas las extinciones contractuales que, con uno u otro motivo, se produzcan por decisión del empleador, como es el caso de que éste decida prescindir de los servicios de una trabajadora durante el período de prueba.

- Entienden, por otro lado, que las diversas garantías del derecho a la no discriminación por razón de sexo de la trabajadora embarazada, que haya dado a luz o en período de lactancia, se plasman, en la normativa comunitaria y en la nacional, en múltiples aspectos de la relación de trabajo, no solamente frente al despido, sino también en otros ámbitos como los afectantes a la seguridad, la higiene y la protección de la salud en el lugar de trabajo; lo que obliga a entender, dada su finalidad global protectora de tales situaciones que afectan especifícamente a la mujer, que no existe fundamento aunque hipotéticamente no se proclamara expresamente en la normativa aplicable, para efectuar distinciones atendida la naturaleza de la relación de servicios o en base a que para su válida extinción en determinados supuestos se exija o no la concurrencia formal de expresión de causas de diverso carácter. 


\section{STC de 10 de Octubre de 2013 y voto particular}

Recurrida en amparo la referida resolución, se dictó sentencia por el Tribunal Constitucional en fecha 10 de Octubre de 2013 denegando el amparo solicitado, considerando asimismo improcedente la aplicación de la regla sobre la nulidad objetiva del despido en caso de embarazo al desistimiento empresarial durante el período de prueba.

La demandante de amparo planteaba la cuestión de determinar si resultaba contraria al derecho a la tutela judicial efectiva, en relación con el derecho a la no discriminación por razón de sexo, la interpretación y aplicación de la ley efectuada por los órganos judiciales en el caso considerado, que habían rechazado la pretensión de la recurrente de extender la regla sobre la nulidad automática del despido en caso de embarazo establecida por el art.55.5.b) E.T. tras la reforma introducida por la Ley 39/1999, al supuesto de desistimiento empresarial durante el período de prueba, considerando las Sentencias impugnadas que para declarar nula la extinción del contrato de una trabajadora embarazada durante el período de prueba es precisa la acreditación del carácter discriminatorio de la decisión extintiva.

Argumentaba el Tribunal Constitucional que la Sentencia dictada por la Sala de lo Social del Tribunal Supremo consideraba que el problema planteado debía ser abordado desde la óptica de la protección frente a la decisión extintiva derivada del derecho fundamental a la no discriminación por razón de sexo (art.14CE), sin que resultara aplicable al desistimiento empresarial durante el período de prueba la regla sobre la nulidad objetiva del despido en caso de embarazo establecida por el art.55.5 b) E.T., dada la distinta naturaleza jurídica de las instituciones del despido y de la extinción del contrato en el período de prueba.

Que el legislador sólo ha ampliado la protección de la trabajadora embarazada, tras la Ley 39/1999 para los supuestos de despido causal, por lo que la extensión de esa protección prevista en el art.55.5 b) ET a otras causas extintivas por via analógica (art.4.1 del Código Civil), sólo sería posible si existiese una identidad de razón esencial entre el despido causal y esas otras causas de extinción del contrato de trabajo. Entienden que las diferencias entre el desisitimiento empresarial durante el período de prueba y el despido son sustanciales de tal modo que no puede aplicarse la via analogia. Así mientras que en el despido la ley exige requisitos de forma, el desistimiento empresarial durante el período de prueba no queda sujeto a formalidad alguna. De este modo entiende el Tribunal Supremo que más allá del supuesto de la decisión extintiva con vulneración de derechos fundamentales que acarrea la declaración de nulidad tanto si se trata de despido como de desistimiento empresarial en período de prueba, aplicándose en este caso las reglas de distribución de la carga probatoria en los mismos términos previstos para el despido nulo, no cabe extender por analogía la protección dispensada para el despido en el art.55.5 b) ET.

Considera el TC que los razonamientos del TS satisfacen plenamente las exigencias del canon de razonabilidad y motivación reforzadas del derecho fundamental del derecho a la tutela judicial efectiva (art.24.1CE) que impone la afectación del derecho a la no discriminación por razón de sexo (art.14 CE). 
Es de destacar el voto particular emitido por el Magistrado Fernando Valdés Dal-Ré9 que señala que las premisas de toda vulneración del art. 14 CE son las dos siguientes:

- la concurrencia del factor protegido (el embarazo como realidad biològica enlazada al género)

- la existencia de un perjuicio asociado (la extinción del contrato de trabajo).

Por otro lado, indica que pese a la diferente naturaleza existente entre el despido causal y el desistimiento empresarial durante el período de prueba, una y otra premisa concurren en ambas modalidades extintivas. Los factores justificativos de una tutela antidiscriminatoria se dan por igual en las extinciones causales y en las no causales, existiendo pues tanto un equivalente imperativo de protección como una identidad de factor protegido en presencia.

Objeta a la Sentencia de la mayoría que asigna una menor protección a la embarazada en período de prueba, minusvalorando la vigencia de los derechos fundamentales precisamente en los escenarios contractuales de mayor precariedad laboral -en el período de prueba frente al régimen extintiva ordinario del contrato de trabajo-.

Por útlimo manifiesta que propuso un overrulling ${ }^{10}$ dirigido a enunciar una protección integral del embarazo frente a la extinción del contrato de trabajo, pretendiendo juzgar, a mi entender, en ese caso con perspectiva de género, disponiendo que "es verdad que, como dejó escrito la STC 182/2005, de 4 de julio, el art.14 CE no consagra la promoción de la maternidad o de la natalidad; pero no es menos verdad que sí excluye, como también recordaba ese pronunciamiento, toda distinción o trato peyorativo a la mujer en la relación laboral fundado en dichas circunstancias. Las determinaciones normativas, los actos empresariales o las interpretaciones que diferencien la tutela antidiscrimatoria entre situaciones que precisen, por razón de embarazo, la misma protección, serán, en suma, contrarias al art.14 CE por imperativo constitucional. Sólo así se asegura el contenido esencial del derecho en la máxima irradiación que exige una norma de sistema, como es la interdicción de discriminación, cuyos presupuestos conceptuales se entrelazan de manera inescindible con la noción de igualdad substancial, al responder a un propósito de reequilibrio y superación en nuestro Estado social de Derecho de ciertos tratamientos peyorativos que sufren grupos o colectivos en razón de un elemento que los caracteriza, y cuya vulneración atenta contra los valores de la dignidad de la persona y de los derechos inviolables que le son inherentes (art.10CE)."

\footnotetext{
${ }^{9}$ Voto particular al que de adhirieron la Magistrada Adela Asua Batarrita y los Magistrados Luis Ignacio Ortega Alvarez y Juan Antonio Xiol Ríos

${ }^{10}$ El articulo 13 de la Ley 2/1979, del Tribunal Constitucional, dispone que "Cuando una Sala considere necesario apartarse en cualquier puento de la doctrina constitucional precedente sentada por el Tribunal, la cuestión se someterá a la decisión del Pleno". El precepto, que viene a acoger la técnica del overruling, contempla el hecho de que una Sala considere necesario apartarse en cualquier aspecto de la jurisprudencia o doctrina constitucional fijada bien por la otra Sala, bien por el propio Tribunal en Pleno. "Los overrulings de la jurisprudencia constitucional”. Fernández Segado, Francisco. Revista de ciencias jurídícas y sociales. № 3. 2006. Pág.28
} 


\section{Reforma del articulo 14 del Estatuto de los Trabajadores por el R.D-Ley 6/2019}

El overrulling al que se hacía alusión en la mencionada resolución se ha plasmado legalmente en el Real Decreto-ley 6/2019, de 1 de marzo, de medidas urgentes para garantia de la igualdad de trato y de oportunidades entre mujeres y hombres en el empleo y la ocupación, Real Decreto-ley que ha sido convalidado en la sesión de la Diputación Permanente de 3 de Abril de $2019^{11}$, habiéndose referido la Vicepresidenta del Gobierno y Ministra de la Presidencia, Relaciones con las Cortes e Igualdad a que se trata de "armonizar y hacer compatible la maternidad con la consideración de ciudadanas y de trabajadoras de las mujeres de este país, particularmente de las más jovenes"

En el apartado cinco del articulo 2 del referido Real Decreto-ley, -precepto que reforma artículos del Estatuto de los Trabajadores- que se modifican los apartados 2 y 3 del articulo 14 , disponiendo el párrafo segundo del apartado 2 que es el que se refiere a la materia que nos ocupa que "La resolución a instancia empresarial será nula en el caso de las trabajadoras por razón de embarazo, desde la fecha de inicio del embarazo hasta el comienzo del período de suspensión a que se refiere el articulo 48.4, o maternidad, salvo que concurran motivos no relacionados con el embarazo o maternidad".

Ya en la Proposición de Ley para garantizar la igualdad de trato y de oportunidades entre mujeres y hombres en el empleo y la ocupación publicada en el Boletín Oficial de las Cortes Generales de 7 de Septiembre de 2018, no 306-1, en la Exposición de Motivos se indicaba que como consecuencia de ciertos pronunciamientos judiciales, se introducía expresamente en el articulo 14 del Real Decreto Legislativo 2/2015, de 23 de octubre, una previsión específica protectora de la mujer embarazada o que haya dado a luz durante el período de prueba, regulando el articulo 17 las garantías en el período de prueba, disponiendo el apartado primero que "1. Será nula y sin efecto la resolución del contrato de trabajo durante el periodo de prueba de las trabajadoras por razón de embarazo, desde la fecha de inicio del embarazo hasta el comienzo del periodo de suspensión a que se refiere el artículo 48.4, y maternidad, salvo que concurran motivos no relacionados con el embarazo o la maternidad".

Es de destacar la expresión que utiliza el precepto, que establece que "La resolución a instancia empresarial será nula en el caso de las trabajadoras por razón de embarazo" -a diferencia de la empleada en los artículos 53 y 55 en relación a la nulidad objetiva del despido objetivo y del despido disciplinario de las trabajadoras embarazadas, respectivamente, que hacen alusión, ambos preceptos, a la nulidad del despido de las "trabajadoras

\footnotetext{
${ }^{11}$ Consta en el Diario de Sesiones del Congreso de los Diputados, en la sesión de la Diputación Permanente no 9 celebrada el miércoles 3 de Abril de 2019, la convalidación del Real Decreto Ley 6/2019, de 1 de marzo, de medidas urgentes para garantia de la igualdad de trato y de oportunidades entre mujeres y hombres en el empleo y la ocupación. Sometido a votación se aprobó por 40 votos a favor y 25 en contra; sometida a votación su tramitación como proyecto de ley por el procedimiento de urgencia, se rechazó por 12 votos a favor y 53 en contra. La Vicepresidenta del Gobierno y Ministra de la Presidencia, Relaciones con las Cortes e Igualdad (Calvo Poyato) en la sesión para la convalidación del mismo manifestó que “...el referido Real Decreto tiene mucho que ver con alguna meta que en el futuro podamos alcanzar, y es que nuestra Constitución, en una posible reforma, comprenda un principio rotundo de igualdad entre hombres y mujeres, como lo tienen la Constitución alemana, la francesa, la italiana o tantes otras que en el contexto de la Unión Eupea han ido haciendo modificaciones constitucionales para obligar estrictamente al principio de igualdad de derechos entre hombres y mujeres". Cabe destacar que pese a la relevancia de la reforma del articulo 14 del E.T., no se hizo ninguna referencia a la misma ni en la intervención de la Vicepresidenta del Gobierno ni en las intervenciones de los diferentes grupos parlamentarios.
} 
embarazadas"- considerando que habría sido más acertado la utilización de esta última expresión, a efectos de no ocasionar duda alguna sobre la finalidad de la reforma que no es otra que establecer la nulidad objetiva de la extinción del contrato de trabajo por desistimiento del empresario durante el período de prueba en el caso de que se trate de una trabajadora embarazada, no siendo necesario alegar circunstancias concretas en las que fundamentar la existencia de un presumible trato discriminatorio como se requería con antelación a la modificación del precepto llevado a cabo por el Real Decreto-ley 6/2019, de 1 de Marzo, de medidas urgentes para garantía de la igualdad de trato y de oportunidades entre mujeres y hombres en el empleo y la ocupación.

\section{Conclusiones}

Ya vaticinó el Magistrado de la Sala de lo Social del Tribunal Superior de Justicia de Galicia Fernando Lousada Arochena ${ }^{12}$ la "futura defunción" de la doctrina constitucional, al marcar la perspectiva de género el signo de nuestros tiempos, señalando que la fuerza expansiva de la igualdad como aspecto derivado de su dimensión objetiva o institucional para mejorar los derechos subjetivos de las personas a la igualdad de sexos, debiera conducir a una reconfiguración del contenido esencial de la prohibición por discriminación del articulo 14 de la CE, entendida en una clave de género. En caso contrario, muchas mujeres y sus familias sufrirán perjuicios , y más aún en la medida en que determinadas nuevas modalidades de contratación laboral introducidas en las últimas reformas admiten períodos de prueba de un año. ${ }^{13}$ Estos períodos de prueba tan dilatados en el tiempo hacen decaer lo que es la finalidad del período de prueba -posibilitar el conocimiento recíproco entre las partes del contrato, de manera que el empresario pueda valorar las aptitudes del trabajador y la conveniencia de mantener el vinculo contractual ${ }^{14}$ - por lo que es un argumento más a favor de la extensión de la aplicación de la nulidad objetiva a las extinciones de contrato por desistimiento del empresario realizadas durante el período de prueba a la trabajadora embarazada, dado que pierde fuerza la distinción entre la naturaleza de una y figura jurídica y otra -desistimiento del empresario durante el período de prueba y despido-.

Por todo lo anteriormente expuesto cabe destacar la relevancia de la reforma operada en el artículo 14 del E.T. por el Real Decreto-ley 6/2019, de 1 de Marzo, de medidas urgentes para garantía de la igualdad de trato y de oportunidades entre mujeres y hombres en el empleo y la ocupación, entendiendo plenamente aplicable la jurisprudencia de la Sala de lo Social del Tribunal Supremo sobre el carácter automático de la declaración de nulidad en el supuesto de que el despido -en este caso, la extinción del contrato por desis-

\footnotetext{
${ }^{12}$ GALLEGO MOYA, FERMÍN. "El período de prueba en el Contrato de Trabajo". Problemas actuales a la luz de la jurisprudencia y de los convenios colectivos. Editorial Aranzadi S.A. 2016. Pág.406

${ }^{13}$ Lousada Arochena, José Fernando, Magistrado Especialista del Orden Social del Tribunal Superior de Justicia de Galicia. "Prohibición de despido de las trabajadoras embarazadas y período de prueba".Revista de Derecho Social no 63, 2013.Pág.154

${ }^{14}$ STS de 12 de Noviembre de 2007, no rec.4341/2006
} 
timiento del empresario durante el período de prueba- de la trabajadora se produzca estando la misma embarazada, aunque el empleador no tenga conocimiento del embarazo, porque el precepto legal es configurador de una nulidad objetiva, que actúa en toda situación de embarazo, al margen de que existan o no indicios de tratamiento discriminatorio o, incluso, de que concurra o no un móvil de discriminación. 